\title{
Ice Slurry on Outdoor Running Performance in Heat
}

\author{
Authors \\ Affiliations \\ Z. W. Yeo ${ }^{1}$, P. W. P. Fan' ${ }^{2}$ A. Q. X. $\mathrm{Nio}^{2}$, C. Byrne' ${ }^{3}$, J. K. W. Lee \\ ${ }^{1}$ Department of Physiology, Yong Loo Lin School of Medicine, National University of Singapore \\ ${ }^{2}$ Defence Medical \& Environmental Research Institute, DSO National Laboratories, Military Physiology Laboratory, Singapore \\ ${ }^{3}$ School of Sport and Health Sciences, University of Exeter, United Kingdom
}

\author{
Key words \\ internal cooling \\ endurance \\ heat \\ thermoregulation
}

accepted after revision

January 31, 2012

\section{Bibliography \\ Dol http://dx.doi.org/ \\ 10.1055/s-0032-1304643 \\ Published online: \\ June 22, 2012 \\ Int J Sports Med 2012; 33: \\ 859-866 @ Georg Thieme \\ Verlag KG Stuttgart · New York \\ ISSN 0172-4622}

Correspondence

\section{Dr. Jason KW Lee, PhD}

Defence Medical \& Environmental Research Institute DSO National Laboratories Military Physiology Laboratory 27 Medical Drive, \#09-01

117510 Singapore

Tel.: +65/6485/71 06

Fax: +65/6485/71 27

Ikaiwei@dso.org.sg

\section{Abstract \\ $\nabla$}

The efficacy of ingestion of ice slurry on actual outdoor endurance performance is unknown. This study aimed to investigate ice slurry ingestion as a cooling intervention before a $10 \mathrm{~km}$ outdoor running time-trial. Twelve participants ingested $8 \mathrm{~g} \cdot \mathrm{kg}^{-1}$ of either ice slurry $\left(-1.4^{\circ} \mathrm{C}\right.$; ICE) or ambient temperature drink $\left(30.9^{\circ} \mathrm{C}\right.$; $\mathrm{CON}$ ) and performed a 15-min warm-up prior to a $10 \mathrm{~km}$ outdoor running time-trial (Wet Bulb Globe Temperature: $\left.28.2 \pm 0.8^{\circ} \mathrm{C}\right)$. Mean performance time was faster with ICE $(2715 \pm 396 \mathrm{~s})$ than CON (2730 $\pm 385 \mathrm{~s}$; $\mathrm{P}=0.023)$. Gastrointestinal temperature $\left(\mathrm{T}_{\text {gi }}\right)$ reduced by $0.5 \pm 0.2^{\circ} \mathrm{C}$

\section{Introduction}

\section{$\nabla$}

Elevated body core temperature $\left(\mathrm{T}_{\mathrm{c}}\right)$ during exercise in hot environments has been shown to reduce both endurance performance $[1,28]$ and endurance capacity (i.e., time-to-exhaustion) $[11,16,17]$. These detrimental effects of elevated $\mathrm{T}_{\mathrm{c}}$ can be mitigated by pre-exercise cooling strategies. Pre-exercise cooling lowers $\mathrm{T}_{\mathrm{c}}$ by inducing a heat debt to the body. This increases heat storage capacity and allows greater metabolic heat production, and delays the onset of fatigue as a result of exercising in the heat. To date, pre-exercise cooling has mainly been achieved via external cooling methods such as cold water immersion $[9,22,28]$, wearing of ice vest $[3,8]$ and cold air exposure $[13,23]$. Although proven to be effective, the field application and practicality of these methods have been challenged [31].

Acknowledging the criticism against external pre-cooling methods, recent studies have employed the more convenient, more practical and less logistically demanding internal precooling strategy of ingesting cold fluid or ice after ICE ingestion compared with $0.1 \pm 0.1{ }^{\circ} \mathrm{C}$ $(\mathrm{P}<0.001)$ with CON. During the run, the rate of rise in $\mathrm{T}_{\mathrm{gi}}$ was greater $(\mathrm{P}=0.01)$ with ICE than with CON for the first $15 \mathrm{~min}$. At the end of timetrial, $\mathrm{T}_{\text {gi }}$ was higher with ICE $\left(40.2 \pm 0.6^{\circ} \mathrm{C}\right)$ than CON $\left(39.8 \pm 0.4^{\circ} \mathrm{C}, \mathrm{P}=0.005\right)$. Ratings of thermal sensation were lower during the cooling phase and for the first kilometre of the run $(-1.2 \pm 0.8$; $\mathrm{P}<0.001)$. Although ingestion of ice slurry resulted in a transient increase in heat strain following a warm up routine, it is a practical and effective pre-competition cooling manoeuvre to improve performance in warm and humid environments. slurry $[12,24,25,34]$. Lee et al. [25] demonstrated in eight healthy males that ingesting cold $\left(4^{\circ} \mathrm{C}\right)$ versus warm $\left(37^{\circ} \mathrm{C}\right)$ fluids before and during exercise in a hot environment prolonged cycling time to exhaustion by $23 \pm 6 \%$. Subsequently, Siegel et al. [34] rationalised that ice slurry would have a higher heat storage capacity through latent heat of fusion due to the phase change from ice to water. They showed that preexercise ingestion of ice slurry $\left(-1^{\circ} \mathrm{C}\right)$ versus cold fluid $\left(4^{\circ} \mathrm{C}\right)$ was effective in lowering rectal temperature $\left(\mathrm{T}_{\mathrm{re}}\right)$ by $0.66 \pm 0.14^{\circ} \mathrm{C}$ and extended the ensuing running time to exhaustion by $19 \pm 6 \%$. An unexpected and novel finding was that end-exercise $\mathrm{T}_{\mathrm{re}}$ was significantly higher after the ingestion of ice slurry $\left(39.36 \pm 0.41^{\circ} \mathrm{C}\right)$ than with cold fluid $\left(39.05 \pm 0.37^{\circ} \mathrm{C} ; \mathrm{P}=0.001\right)$.

Whilst such laboratory findings are promising, the practical impact of ingesting cold fluid or ice slurry is unknown as it has yet to be investigated in a field setting. In the field, air velocity exerts a significant impact on rates of heat storage, and hence thermoregulation during exercise, but this environmental factor has been overlooked in most laboratory trials [33]. For instance, the rate 
Table 1 Participant characteristics. Values are in mean \pm standard deviation.

\begin{tabular}{|llll|}
\hline & Male $(\mathbf{n = 8})$ & Female $(\mathbf{n}=\mathbf{4})$ & All $(\mathbf{n = 1 2})$ \\
\hline age (years) & $23.9 \pm 1.4$ & $21.3 \pm 2.6$ & $23.0 \pm 2.2$ \\
\hline mass $(\mathrm{kg})$ & $63.9 \pm 9.4$ & $56.6 \pm 6.3$ & $61.5 \pm 9.0$ \\
\hline height $(\mathrm{m})$ & $1.70 \pm 0.06$ & $1.64 \pm 0.06$ & $1.68 \pm 0.06$ \\
\hline body fat $(\%)$ & $12.9 \pm 4.6$ & $17.8 \pm 3.1$ & $14.6 \pm 4.6$ \\
\hline $\mathrm{VO}_{2}$ peak $\left(\mathrm{ml}^{\mathrm{kgg}} \mathrm{kg}^{-1} \cdot \mathrm{min}^{-1}\right)$ & $58.1 \pm 7.6$ & $46.8 \pm 5.0$ & $54.3 \pm 8.7$ \\
\hline
\end{tabular}

of heat storage was halved when air velocity was increased from $0 \mathrm{~km} \cdot \mathrm{hr}{ }^{-1}$ to $10 \mathrm{~km} \cdot \mathrm{hr}^{-1}\left(80.8 \pm 22.4 \mathrm{~W} \cdot \mathrm{m}^{-2} \cdot \mathrm{h}^{-1}\right.$ to $42.5 \pm 17.2$ $\mathrm{W} \cdot \mathrm{m}^{-2} \cdot \mathrm{h}^{-1}$ ) and was further reduced by $10.4 \mathrm{~W} \cdot \mathrm{m}^{-2} \cdot \mathrm{h}^{-1}$ when air velocity was increased to the calculated cycling road speed $\left(\sim 33.5 \mathrm{~km} \cdot \mathrm{h}^{-1}\right)$. In addition, the laboratory studies did not incorporate a warm-up routine prior to exercise $[25,34]$. This is important because warm-up exercise is a commonly adopted strategy by runners prior to competitive events and has ergogenic effects on the ensuing exercise. The ergogenic effects of warm-up include elevation of baseline oxygen consumption and postactivation potentiation, enhancement of biomechanical efficiency and psychological preparedness [6]. Because a warm-up exercise also increases muscle temperature [7], this may diminish the effects of a pre-exercise cooling manoeuvre. Moreover, most of these studies that have investigated internal cooling have employed time-to-exhaustion protocols to evaluate endurance capacity and its impact on endurance performance can only be inferred $[25,34]$. A self-paced exercise protocol would serve as a more direct assessment as it provides closer physiological simulation of the actual performance and directly correlates with how athletes fare in a real competition [14].

Therefore, the purpose of the present study was to examine the ingestion of ice slurry as a pre-exercise cooling manoeuvre versus ambient temperature drink on thermoregulation and exercise performance in a field setting. A warm-up routine was incorporated to increase ecological validity. We hypothesised that ice slurry $\left(-1.4^{\circ} \mathrm{C}\right)$ ingestion would significantly reduce $T_{c}$, and improve running performance time in an outdoor $10 \mathrm{~km}$ run, compared with ambient temperature $\operatorname{drink}\left(30.9^{\circ} \mathrm{C}\right)$ ingestion.

\section{Materials and Methods}

$\nabla$

\section{Participants}

12 individuals ( 8 males and 4 females; $\odot$ Table 1 ) volunteered to participate in this study. Ethical approval was granted by the Institutional Review Board and conformed to the international standards as required by the journal [19]. Individuals were required to undergo a mandatory health-screening in a local hospital and were certified fit for study participation by a physician. All volunteers gave their informed consent in writing prior to the commencement of the study and retained the right to withdraw from the study at any time. They were physically active and engaged in at least five sessions of physical activity per week. Participants were familiar with running a $10 \mathrm{~km}$ race, recording an average of seven competitive $10 \mathrm{~km}$ races, ranging from four to more than 20. Majority of the participants represent either their respective institution or running clubs in competitive races. Most of them ran at least one competitive $10 \mathrm{~km}$ race six months prior to the study.

\section{Preliminary measurements}

On the first visit, participants reported to the laboratory where their height was obtained to the nearest $0.1 \mathrm{~cm}$ using a stadiometer (Seca, Brooklyn N.Y, USA) and body mass to the nearest $0.01 \mathrm{~kg}$ using a floor weighing scale (BBA211 Bench Scale, Mettler-Toledo, Germany). Skinfold thickness measurements were taken at four sites (biceps, triceps, subscapular and suprailiac) in duplicates using skinfold callipers (Model HSK-BI-3; Baty International, West Sussex, UK). Body density was calculated according to Durnin and Womersley [15] and percent fat estimated using the equation of Siri [35].

Participants completed a running economy test and a peak aerobic capacity $\left(\mathrm{VO}_{2}\right.$ peak) test on a treadmill in an air-conditioned laboratory (ambient temperature of $\sim 22^{\circ} \mathrm{C}$ with $60 \%$ relative humidity). Expired air was monitored continuously via a facemask and metabolic cart (Cortex Metalyser 3B, Germany). Heart rate was measured continuously by short-range telemetry using a heart rate monitor (Model S610i; Polar Electro Oy, Kempele, Finland). With the treadmill elevated at $1 \%$ gradient, starting speed for the running economy test (ascertained by a steady state $\mathrm{VO}_{2}$ at each stage) was determined by the individual's expected $10 \mathrm{~km}$ race speed minus $1 \mathrm{~km} \cdot \mathrm{h}^{-1}$. The belt speed was increased by $1 \mathrm{~km} \cdot \mathrm{h}^{-1}$ every $3 \mathrm{~min}$ for four stages. Ratings of perceived exertion (RPE) were recorded every $3 \mathrm{~min}$, using the 6-20 point Borg Scale [10].

After the running economy test, participants recovered for 510 min before embarking on the $\mathrm{VO}_{2}$ peak test. An RPE score of 12-13 during the running economy test was used to determine the constant speed for the $\mathrm{VO}_{2}$ peak test. This test commenced at $1 \%$ gradient and the gradient was increased by $1 \%$ every min until volitional exhaustion. Participants were verbally encouraged during the test. Peak aerobic capacity was determined from the average oxygen intake during the final minute of this test. The test was considered valid if the following two criteria were met: (i) heart rate within $10 \%$ of the predicted maximum, (ii) respiratory exchange ratio above 1.15 [2]. A linear regression for $\mathrm{VO}_{2}$ against running speed was calculated and used to predict relative exercise intensity during the $10 \mathrm{~km}$ runs.

\section{Outdoor environmental conditions}

This study took place in Singapore, which is located near the equator (latitude $1^{\circ} 14^{\prime} \mathrm{N}$, longitude $103^{\circ} 55^{\prime} \mathrm{E}$ ). Its climate is characterised by uniformity of temperature $\left(\sim 24-32^{\circ} \mathrm{C}\right)$ and humidity ( $55-95 \%)$. Weather forecast was based on an online meteorological service (www.weather.gov.sg/wip/web/home/ further_outlook) to ensure that the trials took place under consistent outdoor conditions. Dry bulb $\left(T_{\text {dry }}\right)$, wet bulb $\left(T_{\text {wet }}\right)$, globe temperature $\left(\mathrm{T}_{\text {globe }}\right)$, relative humidity and wind velocity during the trials were measured using a portable climate monitoring device (Questemp-15 Area Heat Stress Monitor, Quest Technologies, WI). Wet bulb globe temperature (WBGT) index was calculated as $0.1\left(\mathrm{~T}_{\text {dry }}\right)+0.7\left(\mathrm{~T}_{\text {wet }}\right)+0.2\left(\mathrm{~T}_{\text {globe }}\right)$.

\section{Experimental design}

Each participant completed a familiarisation, and two experimental trials on a $400 \mathrm{~m}$ outdoor running track, ingesting either ice slurry $\left(-1.4^{\circ} \mathrm{C}\right.$; ICE) or ambient temperature drink $\left(30.9^{\circ} \mathrm{C}\right.$; $\mathrm{CON}$ ) in a counterbalanced order. Trials were completed with a minimum of one week following the previous trial. All participants were encouraged to perform their best for each run. Trials were conducted at the same time of the day to control for any circadian variations in $\mathrm{T}_{\mathrm{c}}$. 


\section{Familiarisation}

During the familiarisation, participants and researchers were acquainted with all procedures to be employed during the experimental trials. To familiarise participants with the sensation of ingesting ice slurry, each participant was provided with the actual amount of ice slurry to be ingested during their ICE experimental trial. They were asked to report the occurrence of sphenopalatine ganglioneuralgia (brain freeze), if any. They were also asked to avoid any strenuous physical activity and to record all other physical activities and dietary habits for the preceding day and on the trial day. A diet and physical activity record sheet was kept to facilitate their compliance with the requirements. Participants were encouraged to strictly adhere to these pre-trial control measures for the subsequent experimental trials.

\section{Gastrointestinal temperature}

Gastrointestinal temperature $\left(\mathrm{T}_{\mathrm{gi}}\right)$, measured via an ingestible telemetric pill (VitalSense ${ }^{\circledR}$ temperature sensor) that transmits temperature data every $15 \mathrm{~s}$ in the form of continuous low-frequency radio waves to an external logger (Mini Mitter Co., Inc., Bend, OR, USA), was used as an index of $T_{c}$. Sixteen hours before the commencement of the familiarisation trial, participants were required to swallow a telemetric pill. This enabled researchers to estimate each participant's bowel transit time, and to more accurately advise the time of ingestion for subsequent experimental trials. It is important that the pill sits in the rectum or deep in the gastrointestinal tract for $T_{\text {gi }}$ to be used as an index of $T_{c}$, as ingestion of cold fluid can directly affect sensor temperature [40]. Despite ingesting the pill eight to eleven hours prior, the ingestion of cold drinks has been reported to compromise its accuracy [27]. However, this extended duration (16h) between pill ingestion and trial start also increased the likelihood of pill excretion before exercise and thus, had to be reduced from $16 \mathrm{~h}$ to $10 \mathrm{~h}$ to $7 \mathrm{~h}$ to $4 \mathrm{~h}$, depending on the individual. The time of pill ingestion was kept consistent within each individual between the two experimental trials.

\section{Experimental trials}

Upon arrival at the trial site, each participant's nude body mass was measured to the nearest $0.01 \mathrm{~kg}$ using a floor weighing scale (BBA211 Bench Scale, Mettler-Toledo, Germany). A urine sample, collected mid-stream, was used for measurement of urine specific gravity (USG) using a hand-held refractometer (PAL10S, Atago, Japan). Subsequently, participants were fitted with heart rate monitors (Model S610i; Polar Electro Oy, Kempele, Finland) and were provided with the $T_{g i}$ external logger to be carried in a pouch around their waist during exercise. Heart rate and $\mathrm{T}_{\mathrm{gi}}$ were measured continuously throughout the trial and calculated as $5 \mathrm{~min}$ averages.

During the $30 \mathrm{~min}$ pre-exercise drinking phase, participants ingested $8 \mathrm{~g} \cdot \mathrm{kg}^{-1}$ body mass of sports drink (100 Plus, Fraser and Neave Limited, Singapore; carbohydrate $6.7 \mathrm{~g} 100 \mathrm{ml}^{-1}, \mathrm{Na}^{+}$ $\left.21 \mathrm{mmol} \cdot \mathrm{l}^{-1}, \mathrm{Cl} 11 \mathrm{mmol} \cdot \mathrm{l}^{-1}\right)$ in the form of either ICE or CON. The absolute amount to be consumed was based on individual body mass recorded during the first visit to the laboratory. Ice slurry was prepared using a commercially available ice slurry machine (Two-bowl ice peak machine, IMI Cornelius, US). Servings were administered in six equal aliquots at $5 \mathrm{~min}$ intervals to ensure a standardised ingestion rate. Ratings of thermal sensa- tion (7-point scale; 4) were reported at the start and after ingestion of each aliquot.

A 15 min warm-up phase was provided. Participants were free to perform their preferred exercises before lining up along the start line. The general pattern of participants' self-selected warm up was two to three rounds of jogging around the $400 \mathrm{~m}$ running track or two to three $50 \mathrm{~m}$ strides coupled with stretches of the neck, arms and legs' muscles. They were asked to record their warm-up routine during the familiarisation trial and to repeat it during experimental trials, to prevent $T_{c}$ from being affected by inconsistent amount of metabolic heat generated from different warm-up exercises. The gap between the completion of warm-up and the start of the $10 \mathrm{~km}$ time trial was about $5 \mathrm{~min}$.

Following a mass start, participants were constantly reminded to perform their best. Watches used for heart rate monitoring were masked with a tape to prevent participants from adopting time-based pacing strategies. Performance times were also withheld until the end of the entire study. Ambient temperature water ( $400 \mathrm{~mL}$ prepared in $500 \mathrm{~mL}$ bottles) was available ad libitum to participants at 3.2, 6.0 and $9.2 \mathrm{~km}$ distances. A researcher at the drinks station offered each participant his/her bottle at the respective distances. Participants who drank placed their bottles on a table situated $\sim 100 \mathrm{~m}$ away ( $\bullet$ Fig. 1). Another researcher monitored the number of rounds completed and informed each participant after every $2 \mathrm{~km}$. Upon completion of the run, all measuring equipment was removed, a complete urine sample was collected, and nude body mass was measured.

\section{Fluid balance}

Fluid intake was measured by weighing the drink bottles preand post-run. Changes in nude body mass and volume of urine excreted were used to assess fluid loss or gain during the run. Sweat rate was calculated as (pre-run nude body mass - postrun nude body mass)+ fluid ingested - urine excreted.

\section{Split times}

Separate digital cameras with video recording function (Panasonic, DMC FS20, Japan; Cannon, IXUS 9515, Japan) were placed at the $200 \mathrm{~m}$ and $400 \mathrm{~m}$ marks to record the $200 \mathrm{~m}$ split times of the participants' run.

\section{Subjective ratings}

Ratings of perceived exertion and thermal sensation were reported every $400 \mathrm{~m}$, starting from $0.6 \mathrm{~km}$. Rating of thermal sensation was recorded prior to the run at the start. Visible thermal sensation and perceived exertion scales were placed $15 \mathrm{~m}$ before and after the $200 \mathrm{~m}$ mark, respectively. A video camera (Cannon, Legria HF 20, Japan) and digital cameras (Panasonic, DMC FS20, Japan; Olympus, $\mu$ 760, South Korea) with videorecording function were placed $\sim 5 \mathrm{~m}$ after the scales for participants to report their subjective ratings using hand-signals and/ or verbally. A researcher was stationed at each scale to constantly remind participants to report their subjective ratings.

\section{Statistical analysis}

All statistical computations were performed using the Statistical Package for Social Sciences version 17.0. Data from the ICE and CON trials were paired within an individual. Normality of data was assessed using Shapiro Wilk test. Data which did not follow the normal distribution were analysed using Wilcoxon matchedpair signed rank test. A two-factor repeated measures ANOVA 


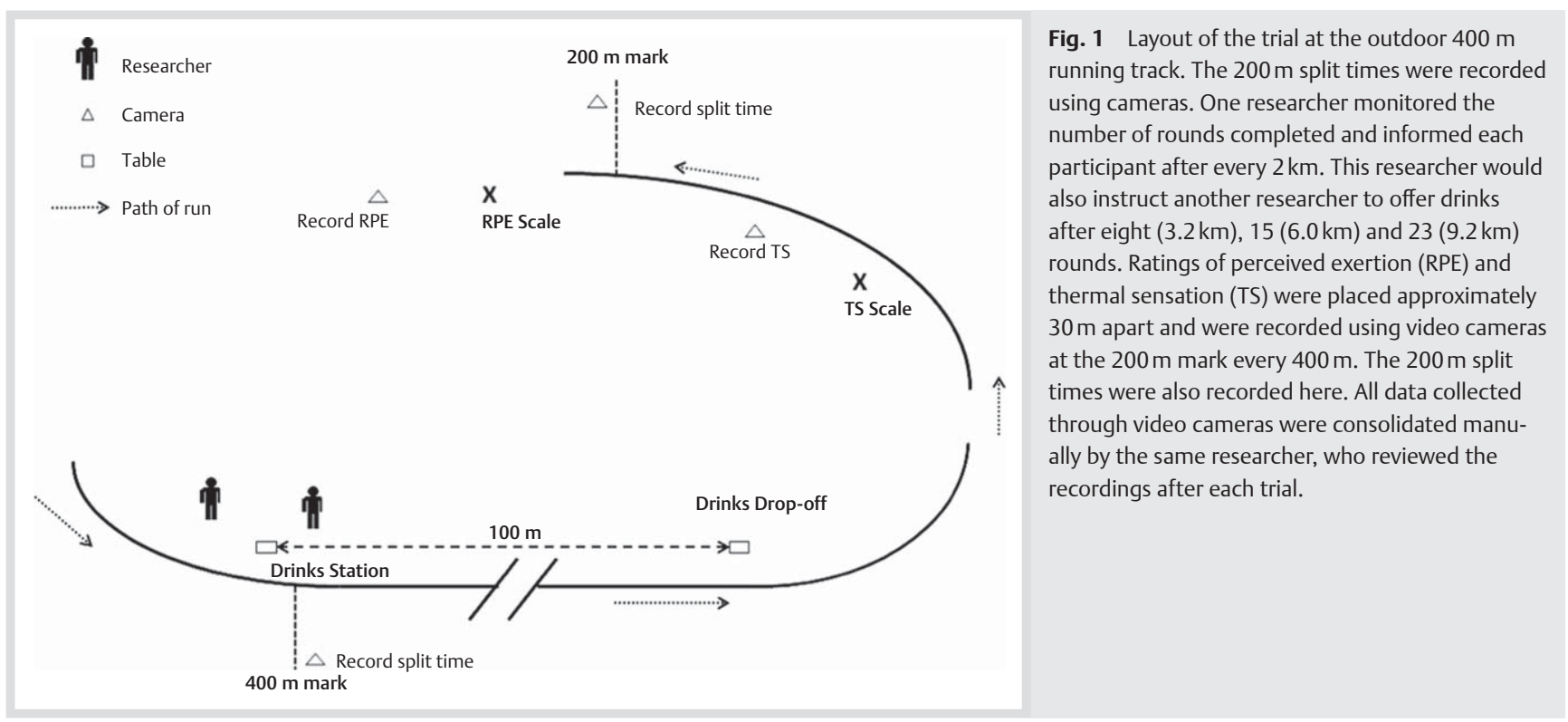

evaluated the changes in the measured variables over time. When a significant F-ratio was obtained, a Student's paired t-test, with a Bonferroni adjustment, isolated differences among treatment means. For all statistical comparisons, a significance of $\mathrm{P}<0.05$ was used. All data are presented as mean \pm standard deviation.

Differences in $10 \mathrm{~km}$ running performance time were also analysed using a magnitude-based inference approach, indicating the effect size of the intervention [5,21]. The coefficient of variation (CV) used in this study was derived directly from the participants' performance times during the familiarisation trial and ice slurry trial, and was established to be $1.2 \%$. Thus, the smallest worthwhile improvement in performance time would be $0.4 \%$ [20]. These data are presented with inference about the true value of pre-exercise ice slurry ingestion-effect on an outdoor $10 \mathrm{~km}$ running time-trial.

\section{Results}

$\nabla$

\section{Environmental conditions and pre-trial hydration status}

There was no difference in mean Wet Bulb Globe Temperature (WBGT) of the sheltered area where the ice slurry or ambient temperature drink were ingested $\left(\mathrm{CON}\right.$ : $27.6 \pm 0.2^{\circ} \mathrm{C}$; ICE: $\left.27.6 \pm 0.2^{\circ} \mathrm{C} ; \mathrm{P}=0.989\right)$. Outdoor WBGT were similar between trials (CON: $28.1 \pm 0.6{ }^{\circ} \mathrm{C}$; ICE: $28.4 \pm 0.9{ }^{\circ} \mathrm{C} ; \mathrm{P}=0.462$ ). Participants were considered to be euhydrated before each trial. This was indicated by both their urine specific gravity (USG; CON: $1.017 \pm 0.008$; ICE: $1.013 \pm 0.009 ; \mathrm{P}=0.124)$ and pre-trial body mass (CON: $60.9 \pm 9.2 \mathrm{~kg}$; ICE: $61.0 \pm 9.1 \mathrm{~kg} ; \mathrm{P}=0.397$ ). One female participant reported a slight sensation of brain freeze after ingesting the $4^{\text {th }}$ aliquot during the ICE trial.

\section{Performance time}

There was no trial order effect on the $10 \mathrm{~km}$ running performance time ( $1^{\text {st }}$ experimental trial: $2733 \pm 416 \mathrm{~s} ; 2^{\text {nd }}$ experimental trial: $2726 \pm 416 \mathrm{~s} ; \mathrm{P}=0.612$ ). Participants performed better during the ICE trial $(2715 \pm 396 s)$ compared with CON trial $(2730 \pm 385 \mathrm{~s}, \mathrm{P}=0.023)$. Mean improvement in performance time was $15 \pm 39$ s or $0.6 \pm 1.4 \%$. There were 11 (out of 12 ) run-

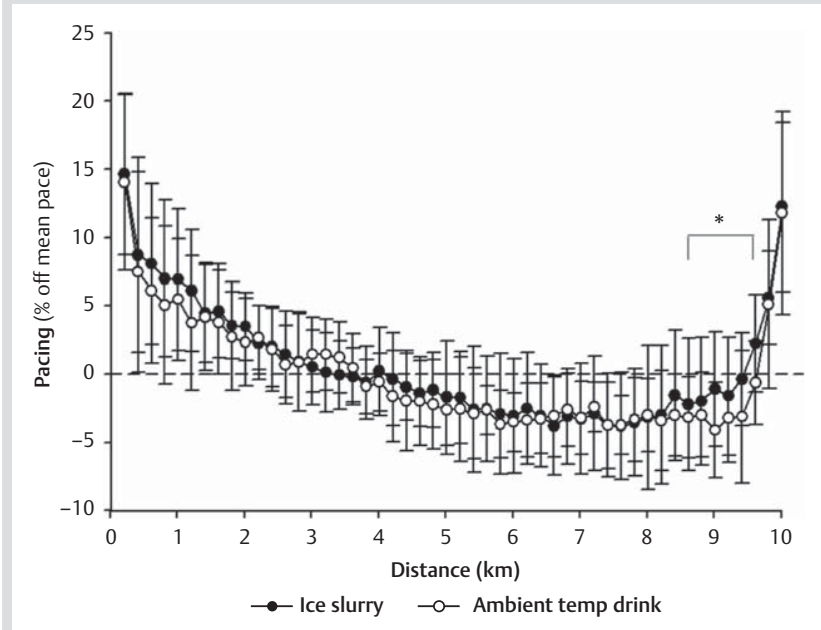

Fig. 2 Pacing for every $200 \mathrm{~m}$ (\% off the mean pace; mean \pm standard deviation) during the $10 \mathrm{~km}$ outdoor run. * denotes ice slurry significantly different from ambient temperature drink $(P<0.05)$. Pacing was significantly faster between 8.6 and $9.6 \mathrm{~km}$ following ice slurry ingestion compared with ambient temperature drink $(P=0.01)$.

ners who performed better when ICE ingestion was employed as the pre-exercise cooling manoeuvre. The time of the only runner who performed worse with ICE ingestion was a large $-102 \mathrm{~s}$, which skewed the mean drastically. When comparison was made using data from the 11 runners who performed better with ICE ingestion, the mean improvement in performance time was $26 \pm 15$ s or $1.0 \pm 0.6 \%$. The likely benefit of ICE ingestion compared with CON ingestion amongst these 11 runners who performed better with ICE ingestion ranges from "trivial to large".

\section{Oxygen uptake $\left(\mathrm{VO}_{2}\right)$ and pacing}

Participants performed at a higher $\% \mathrm{VO}_{2}$ peak during ICE trial $(82 \pm 5 \%)$ compared with the CON trial $(81 \pm 5 \%$; $\mathrm{P}<0.001)$. The mean of the $200-\mathrm{m}$ splits between $8.6 \mathrm{~km}$ and $9.6 \mathrm{~km}$ was faster during the ICE ingestion trial ( $55 \pm 1 \mathrm{~s}$ ) compared with CON trial (56 $\pm 1 \mathrm{~s} ; \mathrm{P}<0.05$; $\bullet$ Fig. 2). There was no difference $(\mathrm{P}=0.515)$ between trials for the rest of the time points. 


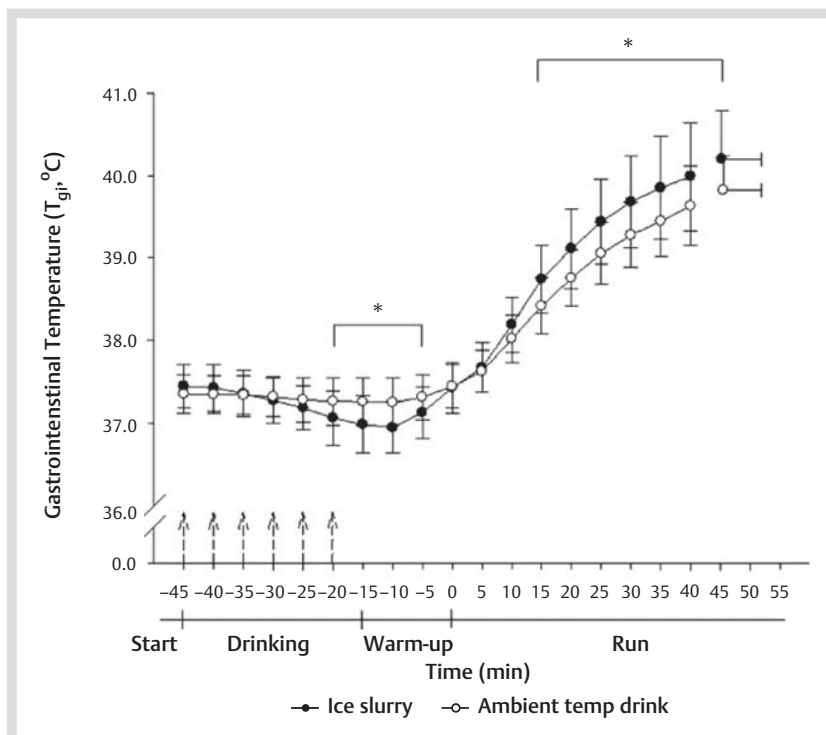

Fig. 3 Gastrointestinal temperature $\left(\mathrm{T}_{\mathrm{gi}} ;{ }^{\circ} \mathrm{C}\right)$ during each experimental trial (mean \pm standard deviation). Arrow denotes when drink was ingested. * denotes ice slurry significantly different from ambient temperature drink $(P<0.05)$. Gastrointestinal temperature was lower during the ice slurry trial from $5 \mathrm{~min}$ before end of the drinking phase to $5 \mathrm{~min}$ before end of warm-up compared with ambient temperature drink trial $(P=0.001)$. At the lowest point, there was a greater decrease in $\mathrm{T}_{\mathrm{gi}}$ during the ice slurry trial $\left(0.5 \pm 0.1^{\circ} \mathrm{C}\right)$ compared with the ambient temperature drink trial $\left(0.1 \pm 0.1^{\circ} \mathrm{C}, P=0.001\right)$. Gastrointestinal temperature was higher during the ice slurry trial compared with ambient temperature drink trial from $15 \mathrm{~min}$ of the $10 \mathrm{~km}$ outdoor run $(\mathrm{P}=0.01)$. At the end of the run, $\mathrm{T}_{\mathrm{gi}}$ was higher in the ice slurry trial compared with the ambient temperature drink trial $(P=0.005)$.

\section{Gastrointestinal temperature $\left(\mathrm{T}_{\mathrm{gi}}\right)$}

Gastrointestinal temperature data from only 11 participants are presented, as one participant excreted the telemetric pill before his CON trial. During the $5 \mathrm{~min}$ rest before the start of the drinking phase (start), there was no difference in $\mathrm{T}_{\mathrm{gi}}\left(\mathrm{CON}: 37.4 \pm 0.2^{\circ} \mathrm{C}\right.$; ICE: $37.5 \pm 0.3^{\circ} \mathrm{C} ; \mathrm{P}=0.144$ ) between trials ( $\odot$ Fig. 3 ). At the end of the drinking phase, ICE ingestion resulted in a greater reduction in $\mathrm{T}_{\mathrm{gi}}\left(0.5 \pm 0.2^{\circ} \mathrm{C}\right)$ compared with $\mathrm{CON}\left(0.1 \pm 0.1^{\circ} \mathrm{C}\right.$; $\mathrm{P}=0.001$ ). Following warm-up exercises and prior to start of the run, $\mathrm{T}_{\mathrm{gi}}$ was similar $\left(37.4 \pm 0.3^{\circ} \mathrm{C}\right.$ vs. $\left.37.4 \pm 0.3^{\circ} \mathrm{C} ; \mathrm{P}=0.841\right)$ between trials. Gastrointestinal temperature remained similar until the $15^{\text {th }}$ min of the run, after which the $\mathrm{T}_{\mathrm{gi}}$ became higher in the ICE trial $\left(39.5 \pm 0.7^{\circ} \mathrm{C}\right)$ compared with the CON trial $\left(39.1 \pm 0.6^{\circ} \mathrm{C} ; \mathrm{P}=0.01\right)$. At completion of the run, end $\mathrm{T}_{\mathrm{gi}}$ was higher in the ICE trial $\left(40.2 \pm 0.6^{\circ} \mathrm{C}\right)$ compared with CON trial $\left(39.8 \pm 0.4^{\circ} \mathrm{C}, \mathrm{P}=0.005\right)$. The mean rate of $\mathrm{T}_{\mathrm{gi}}$ increase was significantly higher $(\mathrm{P}<0.01$; $\odot$ Fig. 4$)$ from -10 to $15 \mathrm{~min}$ of the run in the ice slurry trial compared with ambient temperature drink trial. There was no difference $(P=0.512)$ thereafter between the trials.

\section{Heart rate}

There was no difference in heart rate (CON: $65 \pm 12$ beats $\cdot \mathrm{min}^{-1}$ vs. ICE: $68 \pm 8$ beats $\left.\cdot \mathrm{min}^{-1} ; \mathrm{P}=0.254\right)$ between trials at the start of the trials. Prior to the run, (time $=0 \mathrm{~min}$ ) heart rate was similar (CON:97 \pm 17 beats $\cdot \mathrm{min}^{-1}$ vs. ICE: $98 \pm 14$ beats $\cdot \mathrm{min}^{-1} ; \mathrm{P}=0.840$ ) between trials. It remained similar $(\mathrm{P}=0.359)$ throughout the run and at the end of the run (CON:182 \pm 7 beats $\cdot \mathrm{min}^{-1}$ vs. ICE: $184 \pm 11$ beats $\cdot \mathrm{min}^{-1} ; \mathrm{P}=0.404$ ) between trials.

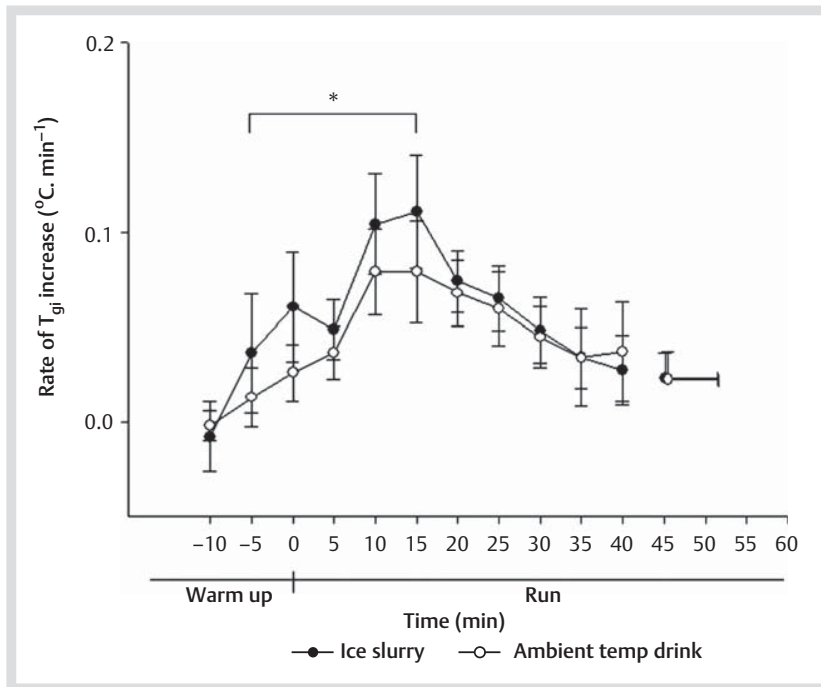

Fig. 4 Rate of $\mathrm{T}_{\mathrm{gi}}$ increase $\left({ }^{\circ} \mathrm{C} \cdot \mathrm{min}^{-1}\right)$ during the outdoor $10 \mathrm{~km}$ run at each experimental trial (mean \pm standard deviation). ${ }^{*}$ denotes ice slurry significantly different from ambient temperature drink $(P<0.05)$. Mean rate of $T_{g i}$ increase was significantly higher $(P<0.01)$ from -10 to 15 min in the ice slurry trial compared with ambient temperature drink trial. There was no difference $(P=0.512)$ thereafter.

\section{Sweat rate and fluid balance}

Ad libitum water intake during the outdoor $10 \mathrm{~km}$ run was simi$\operatorname{lar}$ (CON: $87 \pm 87 \mathrm{~mL}$; ICE: $119 \pm 98 \mathrm{~mL}$; $\mathrm{P}=0.357$ ) between trials. There was no difference in post-run urine volume (CON: $51 \pm 53 \mathrm{~mL}$; ICE: $69 \pm 93 \mathrm{~mL} ; \mathrm{P}=0.271$ ) between trials. Estimated sweat rate was also similar (CON: $1.11 \pm 0.19 \mathrm{~L} \cdot \mathrm{h}^{-1}$; ICE: $\left.1.13 \pm 0.24 \mathrm{~L} \cdot \mathrm{h}^{-1} ; \mathrm{P}=0.576\right)$ between trials. Net body mass loss during the run was similar (CON: $2.0 \pm 0.5 \%$; ICE: $2.1 \pm 0.5 \%$; $\mathrm{P}=0.617)$ between trials.

\section{Subjective ratings}

There was no difference in RPE throughout the outdoor $10 \mathrm{~km}$ run between trials $(\mathrm{P}=0.566$; $\odot$ Fig. 5a). Ratings of thermal sensation were similar (CON: $1 \pm 1$; ICE: $1 \pm 1 ; \mathrm{P}=0.339$ ) between trials before the drinking phase ( $\bullet$ Fig. $\mathbf{5 b}$ ). There was no difference (CON: $1 \pm 1$; ICE: $1 \pm 1 ; P=0.166$ ) in the ratings of thermal sensation in the first $10 \mathrm{~min}$ at rest between trials. The ratings of thermal sensation were lower $(\mathrm{P}=0.001)$ following -35 min onwards, and this trend persisted to the end of the drinking phase. Ratings of thermal sensation were lower $(\mathrm{P}=0.05)$ for up to $1 \mathrm{~km}$ of run, with ICE compared with CON. Subsequently, there was no difference $(P=0.568)$ between trials for the rest of the run.

\section{Discussion}

\section{$\nabla$}

The present study has illustrated that compared with ambient temperature drink at $30.9^{\circ} \mathrm{C}$, ingestion of ice slurry lowered $\mathrm{T}_{\mathrm{c}}$ and allowed $T_{c}$ to rise higher during a self-paced outdoor $10 \mathrm{~km}$ running time-trial. The field setting in which running performance tests were conducted renders novelty to this study, as previous similar investigations were conducted in laboratory settings [32,34]. Ice slurry ingestion led to faster running performance time, specifically by an improved pacing towards the final $2 \mathrm{~km}$ of the time trial. These findings are the first to demonstrate ice slurry ingestion as an effective ergogenic, pre-exercise cooling intervention in a field setting with hot and humid envi- 


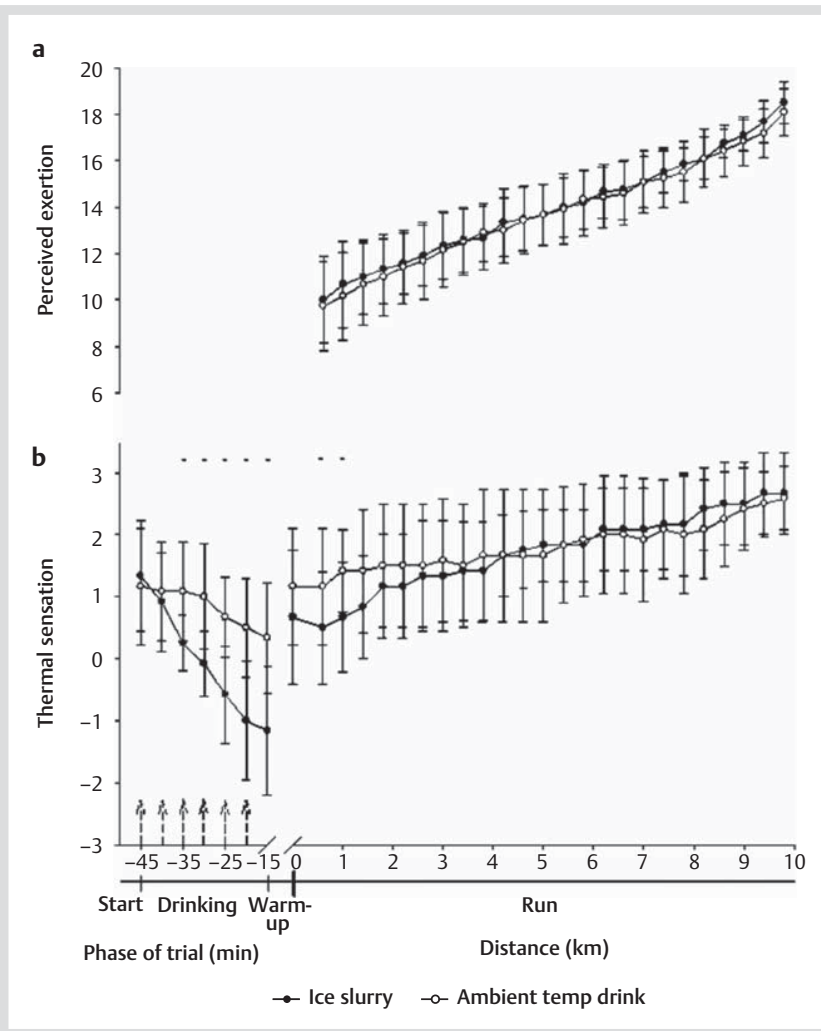

Fig. 5 Ratings of perceived exertion (a) and thermal sensation (b) during each experimental trial (mean \pm standard deviation). Arrow denotes when drink was ingested. ${ }^{*}$ denotes ice slurry significantly different from ambient temperature drink $(P<0.05)$. There was no difference $(P=0.566)$ in ratings of perceived exertion throughout the outdoor $10 \mathrm{~km}$ run between trials. Mean ratings of thermal sensation was lower from third aliquot of drink to end of the drinking phase, with ice slurry compared with ambient temperature drink $(P=0.001)$. Mean ratings of thermal sensation was lower after up to $1 \mathrm{~km}$ of run, with ice slurry compared with ambient temperature drink $(P=0.05)$. There was no difference $(P=0.568)$ between trials for the rest of the run.

ronmental conditions. In addition, the incorporation of individual warm-up routines and the provision of fluid at fixed distances mimic race-like scenarios and further enhance the ecological validity of our findings.

An essential novelty about the present study was the environmental setting in which trials were held. Previous studies were all held in the laboratory, and thus lacked ecological validity. An obvious reason was that environmental variables could easily be controlled and replicated between trials in the laboratory, and therefore removing any potential confounding variables that environmental factors might introduce. In the present study, this concern was accounted for given the similar WBGT recorded between the two experimental trials. The present study was performed in Singapore which is located near the equator. Singapore's climate is hot and humid and is consistent all year round. Thus, allowing environmental controls to be brought to a field setting.

Acknowledging that a substantial amount of energy is required for phase change, researchers have recently evaluated ice slurry ingestion as a pre-exercise cooling method in the laboratory $[34,36]$. Our study was designed to assess this pre-exercise cooling technique in a field setting, with simulated race conditions in the local warm and humid environment. Thermoregulatory responses elicited from ingesting ice slurry in the present study extended the findings from previous laboratory studies.

The heat sink created by ingesting ice slurry was based on the thermodynamic properties of water and the changing of its physical state from solid to liquid. Specific heat capacity $\left(C_{p}\right)$ refers to the quantity of energy required to increase $1 \mathrm{~g}$ of a substance by $1 \mathrm{~K}$. We assumed that properties of the sports drink used in the present study were similar to water, and that ice slurry comprised mostly ice than water. The $C_{p}$ of solid ice is $2.108 \mathrm{~kJ} \cdot \mathrm{kg}^{-1} \cdot \mathrm{K}^{-1}$ and that of liquid water is $4.204 \mathrm{~kJ} \cdot \mathrm{kg}^{-1} \cdot \mathrm{K}^{-1}$. In addition, $334 \mathrm{~kJ} . \mathrm{kg}^{-1}$ of energy is also required for the enthalpy of fusion for phase change from ice to water with ice slurry ingestion. Using the equation from Nadel and Horvath [29] and the $C_{p}$ of human tissue as $3.47 \mathrm{~kJ} \cdot \mathrm{kg}^{-1} \cdot{ }^{\circ} \mathrm{C}^{-1}$, the predicted decrease in $\mathrm{T}_{\mathrm{c}}$ from ingesting $8 \mathrm{~g} \cdot \mathrm{kg}^{-1}$ of ambient temperature drink $\left(30.9^{\circ} \mathrm{C}\right)$ and ice slurry $\left(-1.4^{\circ} \mathrm{C}\right)$ was $\sim 0.1^{\circ} \mathrm{C}$ and $\sim 1.0^{\circ} \mathrm{C}$, respectively. The additional energy required for phase change was responsible for this large difference, as the predicted change in $\mathrm{T}_{\mathrm{C}}$ would be a mere $\sim 0.2^{\circ} \mathrm{C}$ with ingestion of water close to $0{ }^{\circ} \mathrm{C}$. In the present study, a $\mathrm{T}_{\text {gi }}$ reduction of $\sim 0.1^{\circ} \mathrm{C}$ and $\sim 0.5^{\circ} \mathrm{C}$ was observed with ambient temperature drink and ice slurry ingestion, respectively. Compared with the calculated prediction, a smaller actual reduction in $\mathrm{T}_{\text {gi }}$ was observed in the ice slurry trial. This was expected as the calculation assumed ice slurry to be composed of only ice when in reality, the ice slurry comprised ice particles in liquid water. Since substantial energy is derived from the enthalpy of fusion needed for phase change, the calculation would yield an overestimation of drop in $T_{c}$.

We are unable to explain the large negative performance time of the runner who performed worse following the ingestion of ice slurry. However, improvement in performance time of $\sim 1.0 \%$ for the rest of the 11 participants who performed better with ice slurry ingestion was similar to other studies that have investigated pre-exercise cooling manoeuvres and subsequent exercise performance. Arngrimsson et al. [3] showed that wearing a cooling vest compared with a T-shirt during active warm-up exercises improved $5 \mathrm{~km}$ running performance by $1.1 \%$ or $13 \mathrm{~s}$, in the heat ( $32^{\circ} \mathrm{C}$ temperature, $50 \%$ relative humidity). Ross et al. [32] demonstrated that the combined pre-exercise cooling procedure of ingesting $14 \mathrm{~g} \cdot \mathrm{kg}^{-1}$ of ice slurry while being covered with ice towels, enhanced $46 \mathrm{~km}$ cycling time-trial performance by $1.3 \%$ as compared with no intervention. In that study, the effect magnitude of the pre-exercise cooling manoeuvre was established to be "trivial to large", similar to the findings of the present study. More recently, Byrne and colleagues (12) observed a $2.8 \%$ improvement in self-paced distance cycled in $30 \mathrm{~min}$ following cold fluid $\left(4^{\circ} \mathrm{C}\right)$ vs control fluid temperature $\left(37^{\circ} \mathrm{C}\right)$.

In contrast to the recent study by Ross et al. [32], we found simi$\operatorname{lar} \mathrm{T}_{\mathrm{c}}$ at the start of the run between the ice slurry and ambient temperature drink trials. The ingestion of ice slurry prior to the 15 min warm-up might have elicited vasoconstriction, resulting in reduction in peripheral circulation [30]. This would lead to decrease in heat transfer from the body core to the periphery and thus compromise heat dissipation during the 15 min warmup, causing the gradual rise of $T_{c}$ towards baseline before the start of the run. The rate of $\mathrm{T}_{\mathrm{c}}$ increase seen in the present study further supports this physiological response. Its effect was manifested during the initial stage of the run, when $\mathrm{T}_{\mathrm{c}}$ increased at a higher rate during the ice slurry trial compared with the ambient temperature drink trial for up to $15 \mathrm{~min}$. This compromised heat dissipation and increased heat strain during the initial stage of the run. However, improvement in running performance was 
still evident at the late stages of the run. Possible reasons as to why previous studies involving ice slurry did not observe such results could be due to the exclusion of a pre-run warm-up routine [34] or the ingested volume of ice slurry was twice the amount compared to the present study [32], resulting in greater heat debt. In addition, the higher warm-up exercise intensity in the study by Ross et al. [32] might have attenuated the induced peripheral vasoconstriction via the ingestion of ice slurry, in contrast to the relatively low intensity of the self-selected warmup exercises (slow jogs, strides and stretches) performed by our participants. Our observations are similar to that by Uckert and Joch [39], who reported that although pre-exercise cooling through wearing an ice jacket did not result in any differences in $T_{c}$ compared to control, it still enabled participants to perform better.

Pacing generally improved towards the final stages of the $10 \mathrm{~km}$ run after ingestion of ice slurry compared with the ambient temperature drink. This finding agrees with Tucker et al. [37], who found that increased power output during exercise in a cool environment compared with a hot environment only occurred after $\sim 80 \%$ of a self-paced, $20 \mathrm{~km}$ cycling time-trial. Similarly, in an evaluation of whole-body cold water immersion as a preexercise cooling technique, a $30 \mathrm{~min}$ self-paced run on a treadmill revealed an increase in distance covered only after $25 \mathrm{~min}$ [9]. Kay et al. [22] also reported similar findings during a selfpaced cycling performance test. By inferring from blood lactate concentrations, they concluded that whole-body pre-exercise cooling only significantly increased exercise intensity towards the end of exercise. Taken together, pre-exercise cooling enhances exercise performance by allowing athletes to increase their pacing towards the end rather than by maintaining higher intensity throughout the exercise.

Similar to the study by Siegel et al. [34], who employed ice slurry ingestion as a pre-exercise cooling technique in a hot and humid laboratory environment, we observed raised mean $T_{\mathrm{gi}}$ from $15 \mathrm{~min}$ of the run until the end of exercise. The higher $T_{\mathrm{gi}}$ observed at the end of the run can be partly explained by the greater metabolic heat produced during the ice slurry trial, resulting in an enhanced exercise performance. In addition, the sensory effect of ice slurry ingestion may have reduced or inhibited afferent feedback that would mediate a central reduction in muscle recruitment. This would allow the body to tolerate a greater thermoregulatory load or attenuate the importance of the "critical" $T_{c}$, if such a threshold exists [26]. Thus, our participants were able to select higher exercise intensities albeit higher rates of $\mathrm{T}_{\mathrm{gi}}$ increase during the ice slurry trial.

Siegel et al. [34] has suggested that ice slurry ingestion can cause a "physiologically meaningful reduction in brain temperature" and affect the thermo-receptors present. In addition, temperature of ingested liquid has been shown to influence the activity of brain regions associated with reward and pleasantness [18]. Extrapolating the results of Tyler and Sunderland [38] who investigated physiological responses to neck cooling, proximity of the oral introduction of ice slurry and the brain may also have an effect on perceived thermal strain, which may oppose any inhibitory signals due to elevated $\mathrm{T}_{\mathrm{c}}$. In that study, exercise capacity was increased by $\sim 13.8 \%$ compared with no cooling. Participants were also able to tolerate a higher end rectal temperature of $39.6^{\circ} \mathrm{C}$ with neck cooling compared with only $39.2^{\circ} \mathrm{C}$ with no cooling. Coupled with similar RPE scores throughout the run and similar thermal sensation scores after $1 \mathrm{~km}$, it is likely that there exists a central mechanism for the enhanced performance and higher $\mathrm{T}_{\mathrm{gi}}$ observed after ice slurry ingestion.

There are two limitations in this study. Pertaining to the use of the ingestible temperature capsules, it is well known that gastrointestinal transition time is affected by diets and physical activities prior to the experimental trial. We had therefore attempted to control for these factors by ensuring our participants adhered strictly to these pre-trial control measures. In addition, because the ingestion of cold drinks has been reported to compromise its accuracy [27] even when the capsule was ingested 8 to $11 \mathrm{~h}$ prior, we extended the duration between the ingestion of capsule and trial commencement to $16 \mathrm{~h}$. The time of capsule ingestion was kept consistent within each individual between the two experimental trials. The lack of blind treatment may have accentuated the efficacy of ice slurry in the present study.

\section{Conclusion}

The present study has for the first time shown that pre-exercise cooling through the ingestion of ice slurry could indeed be effective in an actual field setting. Ice slurry ingestion is a promising pre-exercise cooling manoeuvre in terms of time-to-effect, logistical demand, practicality and convenience. The transient increase in heat strain following a warm up routine in the ice slurry trial warrants further investigation.

\section{Acknowledgements}

$\nabla$

The authors express their gratitude to all participants in this study. We thank F\&N Singapore for loaning us the ice slurry machine. This study also would not have been possible without the kindness of Anglo-Chinese Junior College, for allowing us to conduct trials on their premises. For his role in data collection, we are deeply appreciative of Mr Ang Wee Hon. We would also like to thank Ms Lydia Law for her helpful comments in the earlier version of this manuscript.

\section{References}

1 Altareki N, Drust B, Atkinson G, Cable T, Gregson W. Effects of environmental heat stress $\left(35^{\circ} \mathrm{C}\right)$ with simulated air movement on the thermoregulatory responses during a $4-\mathrm{km}$ cycling time trial. Int J Sports Med 2009; 30: 9-15

2 American College of Sports Medicine. Interpretation of clinical test data. In: ACSM's Guidelines for Exercise Testing and Prescription. $6^{\text {th }}$ edition Williams \& Wilkins, Philadelphia: 2000; 117-118

3 Arngrimsson SA, Petitt DS, Stueck MG, Jorgensen DK, Cureton KJ. Cooling vest worn during active warm-up improves $5-\mathrm{km}$ run performance in the heat. J Appl Physiol 2004; 96: 1867-1874

4 ASHRAE. Thermal environmental conditions for human occupancy. Atlanta: American Society of Heating, Air-conditioning, and Refrigerating Engineers, Inc 1981

5 Batterham AM, Hopkins WG. Making meaningful inferences about magnitudes. Int J Sports Physiol Perform 2006; 1: 50-57

6 Bishop D. Warm up I: potential mechanisms and the effects of passive warm up on exercise performance. Sports Med 2003; 33: 439-454

7 Bishop D. Warm up II: performance changes following active warm up and how to structure the warm up. Sports Med 2003; 33: 483-498

8 Bogerd N, Perret C, Bogerd CP, Rossi RM, Daanen HA. The effect of precooling intensity on cooling efficiency and exercise performance. J Sports Sci 2010; 28: 771-779

9 Booth J, Marino F, Ward JJ. Improved running performance in hot humid conditions following whole body precooling. Med Sci Sports Exerc 1997; 29: 943-949 
10 Borg GA. Psychophysical bases of perceived exertion. Med Sci Sports Exerc 1982; 14: 377-381

11 Brown NJ, Stephenson LA, Lister G, Nadel ER. Relative anaerobiosis during heavy exercise in the heat. (Abstract) Fed Proc 1982; 41: 1677

12 Byrne C, Owen C, Cosnefroy A, Lee JKW. Self paced exercise performance in the heat after pre-exercise cold fluid ingestion. J Athl Training 2011; 16: 592-599

13 Cotter JD, Sleivert GG, Roberts WS, Febbraio MA. Effect of pre-cooling, with and without thigh cooling, on strain and endurance exercise performance in the heat. Comp Biochem Physiol A Mol Integr Physiol 2001; 128: 667-677

14 Currell $K$, Jeukendrup AE. Validity, reliability and sensitivity of measures of sporting performance. Sports Med 2008; 38: 297-316

15 Durnin JV, Womersley J. Body fat assessed from total body density and its estimation from skinfold thickness: measurements on 481 men and women aged from 16 to 72 years. Br J Nutr 1974; 32: 77-97

16 Galloway SD, Maughan RJ. Effects of ambient temperature on the capacity to perform prolonged cycle exercise in man. Med Sci Sports Exerc 1997; 29: 1240-1249

17 Gonzalez-Alonso J, Teller C, Andersen SL, Jensen FB, Hyldig T, Nielsen B. Influence of body temperature on the development of fatigue during prolonged exercise in the heat. J Appl Physiol 1999; 86: 1032-1039

18 Guest S, Grabenhorst F, Essick G, Chen Y, Young M, McGlone F, de Araujo I, Rolls ET. Human cortical representation of oral temperature. Physiol Behav 2007; 92: 975-984

19 Harriss DJ, Atkinson G. Update - Ethical standards in sport and exercise science research. Int J Sports Med 2011; 32: 819-821

20 Hopkins WG. Magnitude matters: Effect size in research and clinical practice. Med Sci Sports Exerc 2006; 38: 56

21 Hopkins WG, Marshall SW, Batterham AM, Hanin J. Progressive statistics for studies in sports medicine and exercise science. Med Sci Sports Exerc 2009; 41: 3-13

22 Kay D, Taaffe DR, Marino FE. Whole-body pre-cooling and heat storage during self-paced cycling performance in warm humid conditions. J Sports Sci 1999; 17: 937-944

23 Lee DT, Haymes EM. Exercise duration and thermoregulatory responses after whole body precooling. J Appl Physiol 1995; 79: 1971-1976

24 Lee JK, Maughan RJ, Shirreffs SM. The influence of serial feeding of drinks at different temperatures on thermoregulatory responses during cycling. J Sports Sci 2008; 26: 583-590

25 Lee JK, Maughan RJ, Shirreffs SM. Cold drink ingestion improves exercise endurance capacity in the heat. Med Sci Sports Exerc 2008; 40: $1637-1644$
26 Lee JKW, Nio AQX, Lim CL, Teo EYN, Byrne C. Thermoregulation, pacing and fluid balance during mass participation distance running in a warm and humid environment. Eur J Appl Physiol 2010; 109: 887-898

27 Lee JKW, Teo YS, Goh LF, Lim CL. Effects of drink temperature after exercise: Thermoregulatory responses and accuracy of ingestible temperature capsules. Med Sci Sports Exerc 2010; 42: 113

28 Marsh $D$, Sleivert $G$. Effect of precooling on high intensity cycling performance. Br J Sports Med 1999; 33: 393-397

29 Nadel ER, Horvath SM. Peripheral involvement in thermoregulatory response to an imposed heat debt in man. J Appl Physiol 1969; 27: 484-488

30 Nadel ER, Horvath SM, Dawson CA, Tucker A. Sensitivity to central and peripheral thermal stimulation in man. J Appl Physiol 1970; 29: 603-609

31 Quod MJ, Martin DT, Laursen PB. Cooling athletes before competition in the heat: comparison of techniques and practical considerations. Sports Med 2006; 36: 671-682

32 Ross ML, Garvican LA, Jeacocke NA, Laursen PB, Abbiss CR, Martin DT, Burke LM. Novel precooling strategy enhances time trial cycling in the heat. Med Sci Sports Exerc 2011; 43: 123-133

33 Saunders AG, Dugas JP, Tucker R, Lambert MI, Noakes TD. The effects of different air velocities on heat storage and body temperature in humans cycling in a hot, humid environment. Acta Physiol Scand 2005; 183: 241-255

34 Siegel R, Mate J, Brearley MB, Watson G, Nosaka K, Laursen PB. Ice slurry ingestion increases core temperature capacity and running time in the heat. Med Sci Sports Exerc 2010; 42: 717-725

35 Siri WE. Gross composition of the body. Adv Biol Med Phys 1956; 4: $239-280$

36 Stanley J, Leveritt M, Peake JM. Thermoregulatory responses to iceslush beverage ingestion and exercise in the heat. Eur J Appl Physiol 2010; 110: 1163-1173

37 Tucker R, Rauch L, Harley YX, Noakes TD. Impaired exercise performance in the heat is associated with an anticipatory reduction in skeletal muscle recruitment. Pflugers Arch 2004; 448: 422-430

38 Tyler CJ, Sunderland $C$. Cooling the neck region during exercise in the heat. J Athl Train 2011; 46: 61-68

39 Uckert $S$, Joch W. Effects of warm-up and precooling on endurance performance in the heat. Br J Sports Med 2007; 41: 380-384

40 Wilkinson DM, Carter JM, Richmond VL, Blacker SD, Rayson MP. The effect of cool water ingestion on gastrointestinal pill temperature. Med Sci Sports Exerc 2008; 40: 523-528 